\title{
EXPRESIONES JURÍDICAS DEL EJERCICIO DE LA IDENTIDAD PERSONAL Y DE LA AUTODETERMINACIÓN
}

LAWEXPRESSIONSOFTHEEXERCISE OFTHE PERSONALIDENTITYAND SELF-DETERMINATION

Maria Carmen Gete Alonso ${ }^{1}$

Resumen: La dignidad de la persona, su protección y respeto, es principio rector en el que se asientan los ordenamientos jurídicos positivos del área occidental, plasmado en textos universales, internacionales e internos (nacionales). La identidad comporta el reconocimiento de un nombre y apellidos - admitir el conocimiento de los propios orígenes - el respeto y protección en la fijación de las condiciones personales por sí misma, entre las manifestaciones más relevantes. La regulación positiva hecha en las leyes nacionales ni es uniforme, ni completa hasta el punto de que la ausencia de norma comporta una clara violación del derecho de autodeterminación.

Palabras clave: Dignidad. Derechos personales. Autodeterminación. Identidad.

\begin{abstract}
The dignity of the person, their protection and respect, is a fundamental principle on which the positive legal systems of the western area, expressed in universal, international and domestic texts are based. The identity includes recognition of a name - the admission of knowledge of one's origins - the respect and protection in setting personal conditions itself as the most important manifestations. The positive regulation that is made by national laws is not uniform or complete, to the point that the absence of rule involves a clear violation of the right of self-determination, which means serious injury to a fundamental right of the person.
\end{abstract}

Keywords: Dignity. Personals rights. Self-determination. Identity.

Doctora y Licenciada en Derecho; Catedrática de Derecho civil en la Universidad Autónoma de Barcelona; Campus de la UAB, Plaça Cívica, 08193 Bellaterra, Barcelona, España; maricarmen.gete-alonso@uab.cat 


\section{Presentación ${ }^{2}$}

La dignidad de la persona, su protección y respeto, es un principio rector en el que se asientan la práctica totalidad de los ordenamientos jurídicos positivos del área occidental, plasmado como tal en textos jurídicos universales, internacionales y nacionales. En los ordenamientos civiles españoles, se reconoce en la declaración del artículo 10.1 de la Constitución española en el que se lee: "1. La dignidad de la persona, los derechos inviolables que le son inherentes, el libre desarrollo de la personalidad, el respeto a la ley y a los derechos de los demás son fundamento del orden político y de la paz social." A lo que se agrega (apartado 2) que: "Las normas relativas a los derechos fundamentales y a las libertades que la Constitución reconoce se interpretarán de conformidad con la Declaración Universal de Derechos Humanos y los tratados y acuerdos internacionales sobre las mismas materias ratificados por España."

Entre los instrumentos y cartas de derechos humanos internacionales destacan la Declaración universal de los derechos humanos (1948), el Pacto Internacional de derechos civiles y políticos (1966), la Convención sobre los derechos del niño adoptada por la Asamblea general de las Naciones Unidas (1989), la Carta de los derechos fundamentales de la Unión Europea, la Convención Internacional de la ONU sobre los Derechos de las Personas con Discapacidad y su Protocolo Facultativo (2006), o Los principios de Yogyakarta sobre la aplicación del derecho internacional de Derechos Humanos a las cuestiones de orientación sexual e identidad de género (2007), por citar los más significativos. En el ámbito español, además de la Constitución y otros textos, destaca, en lo que afecta a la situación de las personas menores de edad la Ley orgánica 1/1996, de protección jurídica del menor, actualizada recientemente, y la Llei 14/2010, del 27 de maig, dels drets i les oportunitats en la infància i l'adolescència.

En todos ellos, con mayor o menor explicitación se admite el derecho del individuo al reconocimiento y protección de su personalidad jurídica (art. 6 de la Declaración universal de los derechos humanos, art. 12 de la Convención Internacional de la ONU sobre los Derechos de las Personas con Discapacidad). Una personalidad jurídica que comprende el derecho de la persona a su identidad. Un derecho a la identidad que, aunque parece ser concreción de un principio más general, en la actualidad deviene esencial y es un derecho fundamental, ${ }^{3}$ a partir del cual la persona se determina e integra en la sociedad y se reconoce por el Derecho.

Sin embrago, la regulación ni es uniforme, ni completa hasta el punto de que puede llegar a constituir violación del derecho de autodeterminación de la persona. El punto de referencia legal que se toma en este escrito es el ordenamiento español y, en cuanto a la ley civil, junto a la estatal, el derecho civil catalán. ${ }^{4}$

\footnotetext{
En general, véase, Gete-Alonso y Calera y Solé Resina (2013).

3 Es obra clave a partir de la que se asienta la existencia del derecho a la identidad la de Fernández Sessarego (1992).

4 Debe indicarse que una de las características del sistema jurídico español es la coexistencia y pluralidad de ordenamientos civiles, lo que comporta que junto a las leyes generales, aplicables en todo el territorio, deban tenerse en cuenta las leyes civiles autonómicas.
} 


\section{El derecho a la identidad de la persona}

La identidad se engarza en la condición humana de la persona y designa el conjunto de los rasgos propios e inherentes de cada ser, que caracterizan e individualizan frente a los demás, marcan y revelan la diferencia. También, en otro aspecto, indica aquello a través de lo que la sociedad identifica a la persona.

El término se refiere a la conciencia (la percepción y el sentimiento) que cada persona tiene de ella misma como distinta de las demás a la vez que perteneciente al grupo cultural correspondiente. Los rasgos de identidad se componen de las cualidades, las características físicas (morfológicas) y psíquicas, los sentimientos y afectos, los modos de comportarse en la vida peculiares de cada individuo (que constituyen lo propio) y su significación y valoración de los demás en la conformación e integración social.

\subsection{Configuración}

Como se ha indicado, la identidad de la persona abarca el conjunto de los rasgos propios e inherentes, los que caracterizan e individualizan frente a los demás, que marcan o revelan la diferencia. En este significado, la identidad de la persona equivale a la conciencia (la percepción y el sentimiento) que cada persona tiene de ella misma como distinta del resto de humanos por la concurrencia de las cualidades, caracteres, sentimientos y modos de comportarse propios. ${ }^{5}$ Es la identidad que Fernandez Sessarego (1992, p. 21-114) califica como estática.

Junto a esta, es importante remarcar que cuando se habla de la identificación de la persona, en abstracto, también se hace referencia al modo y manera que permite, a los demás (los no yo), el resto de la sociedad, reconocer la individualidad, ${ }^{6}$ la unicidad del ser humano: el individuo (ente único, propio e irrepetible) (Gete-Alonso y Calera, en prensa; Fernández Sessarego, 1992, p. 21-114). La identidad dinámica o proyectiva, como la califica Fernández Sessarego (1992). Dado que la persona, desde el nacimiento, se integra en un grupo social, en la conformación de la identidad junto a lo estrictamente individual (propio o peculiar de cada uno) actúan los valores externos que la rodean; los culturales, éticos y morales, los modelos de persona y las conductas, actitudes y comportamientos que rigen en el entorno, en el grupo determinado, propios del momento histórico que se considere, nuevos, desarrollo o modificación, de lo que está detrás (la herencia de lo anterior.).

\footnotetext{
5 Ambos significados de la identidad se recogen en el Diccionario de la Real Academia de la lengua española, en particular, el que se refiere a la percepción que cada uno tiene de lo que es, se ha añadido en la última edición (23 ed.).

6 Según el Diccionario de la Real Academia de la Lengua española (23a ed.), Identificar es: "Reconocer si una persona o cosa es la misma que se supone o busca." Recuérdese que, atendido el significado del término latino (individu), individuo es lo que no se puede dividir, lo que es único.
} 
De ahí que, cuando se analiza la identidad de la persona se haya de tener en cuenta esta doble vertiente, la individual (yo) y la de relación (los demás).

\section{2 Ámbitos}

El ejercicio del derecho a la identidad se manifiesta en distintos ámbitos, desde el reconocimiento de un nombre y apellidos, pasando por las acciones para averiguar los orígenes propios, hasta la admisión, respeto y protección en la fijación de las condiciones personales de cada ser y la presentación de los mismos. La identidad estática y dinámica que se activa a través de la autodeterminación en el ejercicio de la libertad personal.

Desde que nace hasta el momento en que muere la preocupación de la persona busca afirmar su identidad, en un ejercicio de autodeterminación. Esto es, de una parte, fijar y asumir todo aquello que constituye su esencia, su individualidad única e irrepetible y que forma la consciencia de sí, lo que se llama la "auto descripción plena"; de otra, conseguir el reconocimiento de los demás como miembro del grupo social, es decir como individuo integrado en éste por sí y sin reproche alguno porque su ser único coincide con los valores que aquél admite y práctica.

El reconocimiento y protección de la identidad de la persona en los textos jurídicos nacionales es tardío. Si bien, prontamente, se enuncia el derecho de todo ser humano al "reconocimiento de su personalidad jurídica" (art. 6 de la Declaración Universal de Derechos Humanos de 1948), declaración bajo la que se comprende la identidad, habrá que esperar unos años más para encontrar una mención específica y directa de la identidad y sus atributos.

Así sucede, más tarde, en la Convención sobre los Derechos del Niño (1989) en cuyo artículo 8 se menciona con referencia a los menores de edad: "Los Estados Partes se comprometen a respetar el derecho del niño a preservar su identidad, incluidos la nacionalidad, el nombre y las relaciones familiares de conformidad con la ley sin injerencias ilícitas (apartado 1)." A lo que se agrega "Cuando un niño sea privado ilegalmente de algunos de los elementos de su identidad o de todos ellos, los Estados Partes deberán prestar la asistencia y protección apropiadas con miras a restablecer rápidamente su identidad (apartado 2)." Sin embargo, no se define ni se determinan con exactitud qué y cuáles sean los elementos de identidad, de modo que las previsiones positivas son insuficientes.

Es posteriormente cuando, con fundamento en la igualdad se comienza a hablar de la identidad en la esfera individual o íntima y se desarrolla en determinadas esferas poco consideradas hasta entonces, En general, se entiende que la identidad personal comporta varios ámbitos directamente relacionados con la autodeterminación y la configuración de la persona que se corresponden a las condiciones, atributos y conductas de ésta, objeto de regulación, más o menos amplia. No es posible desarrollar in extenso en este escrito cada uno de ellos, pues comprendería, en sí todo el derecho de persona; en este se da noticia del derecho al nombre, el derecho a conocer los orígenes, y la identidad en las condiciones personales, donde se incluye la sexual y la identidad de género, selección que obe- 
dece a que son los que en la actualidad, presentan más conflictividad, por su parca, incompleta, o en su caso inadecuada regulación.

\section{El derecho al nombre}

En el ordenamiento español, la Ley 20/2011 del Registro Civil ${ }^{7}$ proclama abiertamente que "toda persona tiene derecho a un nombre desde el nacimiento", y lo eleva directamente a la categoría de derecho. Aunque en rigor no existe un precepto constitucional que lo formule, la Constitución de 1978 no es ajena al mismo; éste está embebido en "la dignidad de la persona" y es uno de "sus derechos inviolables" que conforman el fundamento del orden jurídico (art. 10.2 CE).

Determina el artículo. 50.1 de la Ley 20/2011 del Registro Civil que "Toda persona tiene derecho a un nombre desde su nacimiento." En este sentido Álvarez Gónzalez y García Rubio (2013) indican que la referencia y admisión

... sería el derecho al nombre recogido en el artículo 24.2 del Pacto Internacional de Derechos Civiles y Políticos, de 16 de diciembre de 1966 ("Todo niño será inscrito inmediatamente después de su nacimiento y deberá tener un nombre") o en la citada Convención sobre los Derechos del Niño, y consistiría en el derecho que corresponde a todo ser humano a que le sea impuesto un nombre o a ser identificado con un nombre desde el mismo momento del nacimiento y, por supuesto, durante toda su vida. ${ }^{8}$ Es el derecho a tener un nombre desde que se es persona y a mantener un nombre hasta que se deja de serlo con la muerte (p. 473).

Señala la Sentencia TEDH de 01.07.2008 (Daroczy contra Hungría) que: "aunque es cierto que los Estados gozan de un amplio margen de apreciación en relación a la regulación de los nombres, no pueden ignorar la importancia que tienen en la vida privada de los individuos; los nombres son elementos centrales en la identificación y definición de cada cual ..."

Se lee en el artículo 7 de la Convención sobre los Derechos del Niño, adoptada por la Asamblea General de las Naciones Unidas que:

1. El niño será inscrito inmediatamente después de su nacimiento y tendrá derecho desde que nace a un nombre, a adquirir una nacionalidad y, en la medida de lo posible, a conocer a sus padres y a ser cuidado por ellos.

2. Los Estados Partes velarán por la aplicación de estos derechos de conformidad con su legislación nacional y las obligaciones que hayan contraído en virtud de los instrumentos internacionales pertinentes en esta esfera, sobre todo cuando el niño resultara de otro modo apátrida.

En la Ley 20/2011 explícitamente el nombre junto a los apellidos, así lo indica en su Exposición de Motivos, ${ }^{9}$ "se configuran como un elemento de identidad del nacido derivado del derecho

\footnotetext{
7 Que entrará completamente en vigor el 30 de junio de 2017. Los artículos que se comentan aquí, sin embargo, en parte están vigentes junto a los de la Ley del Registro Civil de 1957.

8 Albaladejo García, en 1960, después de decir que "Es el nombre medio fundamental de identificación de la persona en la vida social ..." agregaba que "Toda persona debe tener un nombre, y a cada uno corresponde con exclusividad tanto el derecho como la obligación de llevar el suyo y sólo el suyo" (p. 271).

9 Apartado V.
} 
de la personalidad y como tal se incorpora a la inscripción de nacimiento." En consonancia la ley dispone que la identificación de la persona se lleva a cabo a través del nombre y los apellidos (art. 50.2 LRC).

En el artículo 49.1 LRC se fija que "En la inscripción de nacimiento constarán los datos de identidad del nacido consistentes en el nombre que se le impone y los apellidos que le correspondan según su filiación. . " El nombre y apellidos son datos de identificación, no así el sexo al que no se califica directamente como elemento de identidad. Sin embargo, es inexacto que no sea dato de identidad ya que el hecho de que el Registro de fe de del sexo junto a los demás ${ }^{10}$ no exime de su constancia.

El nombre se impone por los progenitores y, en el caso de que se desconozca su filiación es el encargado del Registro Civil el que asigna un nombre y unos apellidos de uso corriente al nacido, también cuando tras haberles apercibido y transcurrido un plazo de tres días no lo hayan hecho (art. 50.3 LRC).

Es en el artículo art. 51 LRC ("Principio de libre elección del nombre propio") el que establece criterios y límites para su asignación; dispone la norma:

El nombre propio será elegido libremente y sólo quedará sujeto a las siguientes limitaciones, que se interpretarán restrictivamente:

$1^{\circ}$ No podrán consignarse más de dos nombres simples o uno compuesto.

$2^{\circ}$ No podrán imponerse nombres que sean contrarios a la dignidad de la persona ni los que hagan confusa la identificación.

$3^{\circ}$ No podrá imponerse al nacido nombre que ostente uno de sus hermanos con idénticos apellidos, a no ser que hubiera fallecido.

En cuanto a los apellidos, cuando se trata de la filiación por naturaleza dependen de la filiación que esté determinada (arts. 49.2 LRC, 109 CCE, 235-2.2 CCCat). Se ha de tener en cuenta que los apellidos de la persona son dos: el de la línea paterna y el de la línea materna. Ahora bien, como no siempre consta la filiación en relación con los dos progenitores, la norma establece los criterios.

En efecto, la regla común es que si la filiación está determinada en la línea paterna y materna son los padres quienes deciden el orden de transmisión de su respectivo primer apellido, antes de la inscripción registral. Si no se ponen de acuerdo o no se han hecho constar los apellidos en la solicitud de inscripción, el encargado del Registro Civil requiere a los progenitores, o a quienes ostentan la representación legal del menor, para que en el plazo máximo de tres días comuniquen el orden de apellidos. Pasado el plazo sin comunicación expresa, el Encargado decide el orden de los apellidos atendiendo al interés superior del menor. Si únicamente está determinada una filiación es ésta la que rige para los apellidos y el progenitor es quien decide el orden de éstos (primero y segundo suyos).

Si la filiación no constaba y se determina con posterioridad, el apellido del progenitor se añade al que existía. En este caso, se aplican las mismas reglas, se acuerda por los padres el orden y en su defecto lo hace el Encargado del Registro civil.

10 El artículo 44.2 LRC 20/2011 señala expresamente: "La inscripción hace fe del hecho, fecha, hora y lugar del nacimiento, identidad, sexo y, en su caso, filiación del inscrito." 
No existe cuestión respecto del primer hijo, la disfunción se manifiesta respecto de los siguientes hijos pues la norma impone que el orden de los apellidos establecido para la primera inscripción de nacimiento determina el orden para la inscripción de los posteriores nacimientos con idéntica filiación.

Analizadas las normas desde el derecho de autodeterminación no existe causa razonable ni proporcional que justifique por qué no existe oportunidad o, mejor, facultad de acordar, ex novo, un orden de los apellidos diferente respecto del segundo hijo y, por supuesto de los posteriores. Ciertamente, puede argüirse que las normas prevén que los hijos, desde la mayoría de edad o la emancipación pueden alterar el orden de los apellidos (arts. 109 CCE, 235-2.3 CCCat), y que por lo tanto son ellos quienes pueden decidir, en último término, cual es. No obstante, nótese que: $1^{\circ}$ - La facultad de imponer el orden de los apellidos es de los padres, no de los hijos y a aquéllos se les limita sin razón; $2^{a}$. Salvo casos bastante excepcionales, ${ }^{11}$ es muy raro que los hijos mayores de edad hagan uso de su facultad de inversión de los apellidos.

Quizá también podría entenderse que la facultad de los progenitores no es ejercicio del derecho a la identidad propia, a contrario de la del hijo, de lo que deriva la fundamentación de la norma; aun así, para mí es claro que es manifestación de la autodeterminación de la relación de filiación (paterna/materna) que siempre es triangular y, en definitiva, del núcleo familiar lo que debería tenerse en consideración por la norma. De la misma manera que recientes leyes especiales y criterios jurisprudenciales han matizado alguna de estas disfunciones, sobre todo en los casos de violencia y en los de determinación posterior de la filiación paterna (cf., STC, Sala 2a , 167/2013 de 7 de octubre y SSTS (Sala civil) 621/2015, de 27 de octubre; 62/2015, de 12 de noviembre; 15/2016, de 28 de octubre y 659/2016, de 10 de noviembre, en las que se toma en consideración del criterio del interés superior del menor).

La situación no difiere demasiado en la filiación por adopción. La adopción determina, como regla, el efecto de la atribución de los apellidos del o de los adoptantes al hijo adoptado (arts. 109 CCE, 235-2.3 CCCat). En general, en la adopción conjunta el orden de los apellidos lo deciden los adoptantes y si no se ponen de acuerdo es la autoridad judicial la que lo determina en el procedimiento de adopción (art. 235-48 CCCat). Aquí, también, el orden acordado para el primer hijo se aplica a los siguientes. En la adopción por una sola persona el adoptado lleva los apellidos del adoptante, quien decide el orden en el que se disponen. En todo caso, como en la filiación por naturaleza, el adoptado, al llegar a la mayoría de edad puede invertir el orden de los apellidos.

En los supuestos de adopción del hijo de la pareja, el adoptado mantiene el apellido del progenitor de origen y se aplican las normas generales en lo que se refiere al orden. Sin embargo, el progenitor y el adoptante pueden solicitar de común acuerdo que el adoptado conserve los dos apellidos de origen como un solo apellido, uniéndolos con un guion y colocando en primer lugar el

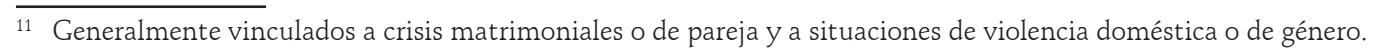


del progenitor superviviente. En este caso, el adoptado debe llevar este apellido junto con el del adoptante. Para llevar a cabo esta unión, es preciso que el progenitor de origen sustituido por la adopción haya muerto y que el adoptado, si ha cumplido los doce años, lo consienta (art. 235-48.2 CCCat).

Finalmente, en la adopción de mayores de edad, supuesto muy específico, ${ }^{12}$ éstos mantienen los apellidos de origen si lo solicitan en el momento de la adopción (art. 235-48.4 CCCat), sino es así se procede conforme a la norma general.

Como se observa, se reiteran, para la adopción, alguna de las disfunciones reseñadas, aunque en esta institución sí se tiene más en cuenta, se valora y considera, los intereses en juego de manera que pocas han de ser las correcciones a hacer para que se respete la autodeterminación.

\section{El derecho a la investigación de los orígenes}

En los supuestos de la filiación adoptiva de menores no familiares y de la filiación (natural) obtenida a través de la aplicación de las técnicas de reproducción asistida cuando es heteróloga, desde hace ya más de una década, se plantea la duda acerca de si debe darse conocimiento de la filiación originaria, o si debe quedar en el anonimato o reservada. El derecho a conocer e investigar acerca de quiénes fueron los progenitores, aunque los ordenamientos fueron renuentes a admitirlo, en la actualidad no está huérfano de regulación, aunque quizá debería completarse.

No cabe duda de que la facultad que permite poner en práctica los medios pertinentes para averiguar quiénes fueron los progenitores biológicos y genéticos está directamente vinculada a la identidad de la persona, tal y cómo ésta se delimita, no sólo físicamente sino mental, psicológicamente, y por consecuencia incide también en su consideración en el grupo social; de ahí que, de manera gradual, se haya admitido. Con todo, la tradición anterior del anonimato, altamente arraigada en la cultura, sobre todo en las latinas, lleva a que no se admita en toda su amplitud, atendiendo a la ponderación de los diferentes intereses que están en juego. Debe recordarse que, frente a la necesidad / interés de la persona que reclama el conocimiento, se erigen no sólo el interés de los padres adoptivos o que han acudido a la práctica de la técnica, sino también el de los progenitores por naturaleza a quienes puede no convenir, por motivos distintos, que se de publicidad de su identidad.

Aunque el fundamento del derecho / facultad parece que debería ser idéntico en ambos casos, debe distinguirse pues mientras en la adopción la persona ya existe, en el caso de las técnicas de reproducción asistida, éstas operan para facilitar la concepción del nuevo ser y, además, interviene la madre por naturaleza, pues en nuestro sistema está prohibida la maternidad por subrogación (art. 10 LTRA).

La Ley 14/2006, de 26 de mayo, sobre técnicas de reproducción humana asistida (LTRA), dispone (art. 5.1) que la donación de las células y gametos siempre es anónima y, además expresa-

12 Pues la adopción en todos los ordenamientos Civiles españoles se configura casi en exclusiva para los menores de edad y, preferentemente, en situación de abandono o riesgo. 
mente establece que debe garantizarse, a los donantes, por los bancos de gametos y los registros de donantes y de actividad de los centros. Esta es la regla general.

Sin embargo del anonimato se prevé el acceso a determinados datos por parte de los hijos, por sí o a través de sus representantes legales y de las mujeres receptoras de los gametos y preembriones. Esta facultad únicamente legitima para obtener información general de los donantes, se entiende de los datos físicos y genéticos de los que se disponga, en ningún caso, de la identidad (art. 5.2 LTRA).

La averiguación de la identidad de los donantes sólo se admite excepcionalmente, cuando concurran circunstancias extraordinarias que comporten un peligro cierto para la vida o la salud del hijo o cuando proceda con arreglo a las Leyes procesales penales y siempre que la revelación sea indispensable para evitar el peligro o para conseguir el fin legal propuesto. En todo caso, la revelación es de carácter restringido y no implica en ningún caso publicidad de la identidad de los donantes; lo que significa que sólo la conoce el hijo (art. 5.5 LTRA). La revelación de la identidad del donante cuando procede no implica en ningún caso determinación legal de la filiación (art. 8.3 LTRA).

De lo indicado se sigue que se distinguen dos tipos de, llamémosles, acciones de indagación del origen: una que puede calificarse como genérica que permite acceder a determinados datos de los padres biológicos; otra, más específica que alcanza a los datos de identidad de éstos pero restringida a situaciones determinadas por la ley.

En inicio, parece razonable el criterio y la distinción entre las dos acciones informativas, aunque, es evidente que, atendidos en general los derechos de la personas en la actualidad, por lo que respecta a la identidad es discutible si es oportuno de una parte mantener la distinción y de otra, para la segunda, si está suficientemente justificada la restricción del anonimato o, si contrariamente, debe ampliarse, en verdad, desaparecer la restricción. ¿̇Por qué sólo en circunstancias extraordinarias que comporten peligro para la salud y en procesos penales? ¿̀Para las situaciones que afectan a la salud no basta con el primer tipo de acción? خCómo se coordinan y complementan una y otra? خCuál es el fundamento si, a fin de cuentas no afecta a la determinación de la filiación que es inamovible? Quien dona su material debería asumir que la persona nacida pueda conocer quién es, sin más trascendencia, como sucede en algún ordenamiento, significativamente el primero en admitirlo Suecia en 1984, al que con posterioridad han seguido otros países, sin que la eliminación del anonimato haya implicado un descenso en las donaciones, ${ }^{13}$ causa que se alega para mantener el anonimato. Pero, en el conflicto entre el derecho del donante y el de la autodeterminación, identidad de la persona żCuál debe prevalecer?.

Las acciones que se regulan en el supuesto de la adopción son similares si bien existen importantes diferencias. Cómo en la reproducción asistida se disocia el derecho a conocer los datos

13 Más ampliamente, vid Garriga Gorina (2007, pp. 167-228).

EJJL 
(art, 235-49 CCCat), de la información acerca de la identidad de los padres biológicos (arts. 180. 6 CC; 235-49 CCCat).

Para dar cumplimiento a esta información, en derecho catalán, además, se establece la obligación de los adoptantes de informar al hijo acerca de la adopción lo antes posible y en todo caso a partir de los doce años, salvo que no sea conveniente para el interés del menor (art. 235-50 CCCat) (puede ser considerada contraria, por ejemplo, la revelación de que el hijo es fruto de unas relaciones incestuosas). Nada se indica acerca de esta obligación en otros cuerpos legales; no obstante, establecido el derecho a conocer los datos es evidente que existe, también, la facultad de exigir a los padres que informen a los hijos acerca de su condición de adoptivos, pues en la mayoría de los casos la única vía que tienen de conocer su condición de adoptivos es a través de los padres.

La acción dirigida al conocimiento de datos biogenéticos de los padres biológicos; acción sólo regulada expresamente en la normativa catalana, aunque quizá, para la del Código civil pueda considerarse comprendida bajo la expresión general "derecho a conocer los datos sobre sus orígenes" (art 180. 6 CC). En la normativa catalana, están legitimados para solicitar los datos biogenéticos (art. 235-49.4 CCCat):

- Los padres adoptivos mientras el adoptado es menor de edad cuando sea necesario para éste. Son dos requisitos que han de concurrir: que los adoptados sean menores de edad y que la causa de la solicitud sea la salud de aquél. En propiedad, esta facultad cómo en la reproducción asistida no comporta una auténtica acción de investigación ya que, en ningún caso, autoriza para dar conocimiento de la identidad de los progenitores.

- A los propios adoptados; aunque la norma no dice nada, puesto que, cuando son menores de edad lo pueden pedir los padres adoptivos se ha de entender que el adoptado es mayor de edad o está emancipado. El único requisito exigido es que sea "en interés de su salud".

En el Código civil español (art. 180.5 CC) los datos los pueden recabar los adoptados a partir de la mayoría de edad y durante su minoría de edad a través de los representantes legales. En este caso, se indica que las entidades públicas asegurarán la conservación de la información de que dispongan relativa a los orígenes del menor, en particular la información respecto a la identidad de sus progenitores, así como la historia médica del menor y de su familia, y se conservarán durante al menos cincuenta años con posterioridad al momento en que la adopción se haya hecho definitiva.

2. De otra, la acción de investigación de los progenitores biológicos (arts. 180.5 CC; 235-49.2 y 3 CCCat).

En la normativa del Código civil español (art. 180.6 CC), donde no se distingue, se legitima a las personas adoptadas a partir de la mayoría de edad o a través de sus representantes legales durante su minoría de edad para

conocer los datos sobre sus orígenes biológicos. Para lo pueden dirigirse a las entidades públicas de protección de menores que prestarán todos los servicios y asesoramiento para hacer efectivo el derecho, que lo han de notificar a las personas afectada. A estos efectos se impone a cualquier entidad 
privada o pública la obligación de facilitar a las entidades públicas y al Ministerio Fiscal, cuando les sean requeridos, los informes y antecedentes necesarios sobre el menor y su familia de origen.

En el derecho catalán de manera más directa y precisa se legitima al adoptado para que, a partir de su mayoría de edad o emancipación, pueda ejercitar acciones que conduzcan a averiguar quiénes son su padre y madre biológicos. En todo caso, la finalidad es puramente la de investigación sin que su resultado afecte a la adopción, ni a la filiación constituida por ella. A tal efecto, se impone a las administraciones públicas el deber de facilitar al adoptado los datos que tengan acerca de su filiación biológica. Con esta finalidad, indica la norma (art. 235-49.3 CCCat), se ha de iniciar un procedimiento confidencial de mediación, previo a la revelación de los datos, en el que tanto el adoptado como el padre y la madre biológicos han de ser informados de las circunstancias familiares y sociales respectivas y de la actitud manifestada por la otra parte respecto del posible encuentro (conocimiento). El ejercicio de esta acción debe efectuarse a cabo sin detrimento del deber de reserva de las actuaciones que impera en toda esta materia (art. 235-49.5 CCCat) y se proyecta, también, a la hora de dar publicidad de la constancia registral de la filiación adoptiva.

No se prevé, ni en una ni en otra normativa el procedimiento en el que se ejercita esta acción de averiguación de la identidad de los progenitores. No obstante, cuando la filiación anterior del adoptado consta en el Registro Civil, la averiguación de la identidad de los progenitores biológicos puede obtenerse aplicando las reglas registrales. Si no es así, o bien la que conste sea de una filiación desconocida (porque no se llegó a determinar) se puede acudir ya a una reclamación en vía administrativa, ante la entidad competente que intervino en el expediente de adopción ya en caso de que ésta se negara a facilitar la información, se puede instar judicialmente.

La deficiencia de regulación se manifiesta, además, en relación a las vías materiales y procedimentales para ejercitar las acciones, tan necesarias como las propias acciones para dar cumplimiento al derecho de autodeterminación / identidad.

\section{El sexo}

Las condiciones y atributos de la persona forman parte de la identidad, de ahí que las normas deban prever medios para procurar su admisión y respeto. Entre ellas la de más relieve es la identidad sexual y de género, no sólo por su trascendencia sino porque aún no ha sido totalmente reconocida.

\subsection{Identidad sexual - identidad de genéro}

En inicio, física o biológicamente, la persona nace con las cualidades o atributos que pertenecen a un sexo concreto que comportan su inclusión desde el momento de adquisición de la personalidad jurídica en uno de los reconocidos, en una sociedad regida por el dimorfismo sexual. Las 
personas, de acuerdo con el aspecto anatómico de los órganos sexuales, externos e internos, se dice para "lo que es normal", que pertenecen ineludiblemente a uno: masculino - femenino, no cabe un tercer sexo, tampoco la ambigüedad o indefinición sexual, ni cabe plantearse la posibilidad de que tenga lugar un cambio de sexo sin que sea completo y alcance a todas las funciones de éste. Además, el comportamiento sexual y la conducta esperada por la sociedad, responde necesariamente a uno de los dos modelos establecidos, pues a través de ellos tiene lugar la identificación oficial.

Este atributo que indica la identidad sexual no se pone en duda ni discute mientras los rasgos, caracteres y conductas coinciden o se ajustan a lo admitido y a los valores del momento. Surge la reivindicación de lo propio (dispar), cuando aflora la situación dispar, muchas veces amagada (tabú social muy anclado), y con base en la dignidad de la persona y sus derechos se cuestionan las reglas y se llama a la asunción de las condiciones de la persona íntegramente. Es entonces, cuando la identificación sexual deviene conflicto que debe resolver la norma.

En general, como se vio en las páginas anteriores, el sexo es dato que ha de figurar en la inscripción de nacimiento y es de identificación (arts. 49 y 50 LRC), no se puede evitar o dejar que su constancia se efectúe en un momento posterior. El problema se presenta para todas las personas en las que existe una diversidad sexual, ya física (interserxuales) ya psíquica (transexuales).

El patrón clásico del dimorfismo sexual que adoptan las normas encierra, también, la conducta o comportamiento sexual que se espera de la persona conforme al sexo físico y, asimismo la asignación concreta de la finalidad derivada: la diferenciación sexual y la identidad de los miembros de la pareja humana orientada, preferentemente, a la reproducción que asegura la pervivencia de la especie.

La persona, en el seno de las sociedades de la cultura occidental a lo largo de la historia en su desarrollo y en la manera de poner en práctica su conducta, es guiada por los que están en su entorno conforme a dicho modelo, de modo que percibe su sexualidad conforme a lo que le indican. De ahí que lo que se separa o no se amolda al cliché o no existe, se oculta y silencia, o se somete a una corrección. Tanto por lo que hace al sexo físico cómo al comportamiento o deseo sexual.

En la puesta en evidencia de la diversidad sexual la constatación de situaciones fuera de la dualidad de sexos, y de las conductas homosexuales y bisexuales, y la asunción de la discordancia sexual entre el corpus y la psique, ha llevado a acuñar lo que se conoce como identidad de género, término bajo el que se comprende algo más que en la estricta, llamémosle así, identidad sexual.

La identidad sexual y la identidad de género, aunque próximas no son lo mismo, ${ }^{14}$ siquiera durante algún tiempo se hayan empleado, y aún parece que se utilizan así, como términos sinónimos. Conviene no confundirlas, ${ }^{15}$ tampoco se ha de mezclar la identidad sexual con la inclinación

14 Obra de referencia es la de Batler (2007).

15 Vid. Valpuesta Fernández (2013, pp. 552-556). 
sexual, inherente a la persona y a la que se debe atender y respetar que tiene su propia caracterización, incluido en la identidad de género.

La denominada identidad sexual, en inicio y en su concepción primigenia, se sitúa en el ámbito puramente biológico y genético. En la identidad sexual, estrictu sensu, el punto de partida es la división de los humanos en dos sexos, lo que es la norma - normalidad -: masculino y femenino. En contraste, el significado de la identidad de género es cultural, social, lo que hace que sea un concepto derivado y no originario, mientras el sexo se predica de la anatomía corporal se entiende que género afecta al ámbito psicosocial.

La identidad de género es la manera en que la persona se manifiesta y actúa durante su vida y sobre todo a partir de que alcanza autonomía y conciencia de sí, cómo se desenvuelve en la sociedad. Comprende la función y las conductas, sentimientos y actitudes que la sociedad atribuye a lo masculino o a lo femenino, en cada período histórico (Valls-Llobet, 2008, p. 99; Valpuesta Fernández, 2013, pp. 552-556) y que la persona presenta. La identidad de género incluye no sólo la percepción exterior, de los demás sino también y particularmente la manera en que la persona se muestra en la vida de relación, o sea su comportamiento, la función que asume y quiere (siente, pertenece a su convicción o ser) por la que es considerada por los demás, con o sin la identidad física.

\subsection{Discordancia: intersexualidad, transexualidad}

La situación de intersexualidad se predica de "los sujetos que nacen con una corporalidad ambigua, en tanto que sus cuerpos no se ajustan a la norma cultural y médica del sistema de dos sexos ... /que/ representan los límites que la naturaleza ofrece a las categorías construidas de «hombre» $\mathrm{y}$ «mujer»" (Balza, 2009, p. 246).

La intersexualidad es una condición de la persona que afecta a su sexo físico, en su apariencia externa e interna, y provoca indefinición, duda, confusión en torno a su inclusión en una de las dos categorías del sexo reconocido. Esta situación por sus características la distancia de la transexualidad y de la orientación sexual. La presentación de la sexualidad confusa impide situar a la persona nacida tanto en el sexo femenino como en el masculino, debido a la alteración en la formación de los órganos internos y externos que determinan el sexo; hasta hace muy poco, se percibía como una situación o condición de anormalidad, frente al patrón de la normalidad que representa el dimorfismo sexual. Esta calificación patológica como anormalidad o deficiencia, que hoy en día se cuestiona y ha marcado su denominación y tratamiento desde la medicina y la clínica, ha influido a la hora de plantear su enclave normativo.

La indefinición sexual de estas personas se concretará más adelante, pues el proceso de formación de los órganos y la identidad se desarrolla a medida que tiene lugar la maduración física, 
emocional y cognitiva y según explican los expertos, alcanza su cenit superada la adolescencia, ${ }^{16}$ de modo que es necesario esperar, paréntesis al no ha atendido la norma pues requiere la identificación del sexo contemporánea al nacimiento. De ahí, a su vez, que la exigencia de atribución de un sexo haya derivado en la práctica de la operación clínica correspondiente para la asignación de uno a escasos días, si es posible, siguientes al nacimiento, sin esperar al resultado de la completa evolución. A su vez, de ahí, la disfunción normativa y que se observe el más absoluto desprecio normativo a la autodeterminación de la persona: al no permitir que sea ella quien decida si debe o no someterse a una intervención quirúrgica.

El reconocimiento de la identidad sexual biológica en el siglo XXI, a día de hoy ha de pasar por admitir también la diversidad y de ahí la indefinición y la ambigüedad sexual física y de género, que es dato de identidad de estas personas. Si se reconoce, lo que ahora no se hace expresamente con la amplitud que sería necesaria, la situación o condición de intersexo debe tener cabida para cumplir con el principio de igualdad y el respeto a la dignidad de las personas. El valor dignidad de la persona debe llevar, en el fondo, a la irrelevancia jurídica del sexo para la identificación que debe desaparecer como dato de identidad jurídico, sin que comporte que se deje al margen por completo.

Los problemas de identidad sexual física, también, se han formulado respecto de otra situación próxima: la transexualidad, ${ }^{17}$ hasta el punto de que, durante un largo tiempo se ha obstaculizado el cambio del registro del sexo publicado. También, desde que las normas dan entrada a la transexualidad, lo que han hecho en los ordenamientos españoles anticipadamente a la situación de intersexualidad, la conclusión obligada ha de ser que se atienda a la voluntad (autodeterminación) de cada uno con referencia a este extremo (la identidad sexual: física en alguno de sus aspectos).

Se lee en la Exposición de Motivos de la Ley 3/2007, de 15 de marzo (reguladora de la rectificación registral de la mención relativa al sexo de las personas) que "La transexualidad . . como un cambio de la identidad de género. ..", desemboca en "ver corregida la inicial asignación registral de su sexo, asignación contradictoria con su identidad de género, así como a ostentar un nombre que no resulte discordante con su identidad."

La transexualidad, según la caracterización seguida en nuestra ley, es el desajuste entre el sexo biológico / genético de la persona y lo que siente, vive y con lo que se identifica que no se acomoda a aquél, por referirse al sexo contrario. La identidad de la persona, sexual y de género, se siente y percibe en sentido opuesto al físico, lo que provoca una discrepancia que es la que se quiere corregir ya físicamente, mediante la cirugía, para conseguir la readaptación al sexo querido (con el que se identifica) y siempre, es decir haya o no intervención quirúrgica, oficialmente, mediante el reconocimiento oficial de la identidad personal.

$\overline{16}$ Vid, el resumen de Zaro (1999, pp. 13 y ss).

17 Sobre esta Vid, Espín Alba (2008). 
En síntesis, como se lee en el artículo 4.1. a) 1 de la Ley 3/2007, es la “. . . disonancia entre el sexo morfológico o género fisiológico inicialmente inscrito y la identidad de género sentida por el solicitante o sexo psicosocial"; o como indica la Ley Foral Navarra 12/2009, de 19 de noviembre (de no discriminación por motivos de identidad de género y de reconocimiento de los derechos de las personas transexuales), los transexuales son (art. 1) "... las personas que adoptan socialmente el sexo contrario al asignado en su nacimiento. .."

La transexualidad, como problema de identidad sexual / de género se revela, en las etapas en las que tiene lugar la identidad, el asentamiento de la persona. Jurídicamente, en nuestro sistema, el cambio de sexo oficial se fundamenta en datos médicos; exige que se cumplan dos requisitos (Ley 3/2007, art. 4): ${ }^{18}$ la diagnosis y acreditación de la disforia de género permanente y estable y que la persona no padece trastornos de personalidad (1) y que haya sido tratada médicamente, al menos durante dos años para acomodar sus características físicas a las correspondientes al sexo reclamado (2). El cambio del sexo oficialmente publicado se asienta en la voluntad y autodeterminación de la persona, unida a la comprobación médica y psicológica de la identidad de género o sexo que la norma denomina psicosocial para justificar que la alteración es de un dato registral (que, se fundó en un dato fisiológico).

Además de esta Ley, con posterioridad una buena parte de las Comunidades Autónomas ha regulado algunos ámbitos, incluidos dentro de sus competencias, relativos a la situación de transexualidad, de la intersexualidad y de la homosexualidad (Cataluña, Baleares, Galicia, Madrid, Murcia, Navarra, País Vasco), sin embargo, se hace necesaria la modificación de las reglas civiles porque aunque se puede afirmar que la concepción jurídica del sexo dista mucho de la originaria sobre la que se asientan la mayor parte de normas jurídicas, aún conviven ambas nociones (la biológica y la jurídica), lo que obliga a una remodelación, en su conjunto, de todas las normas, mejor, a un replanteamiento serio y riguroso acorde con la dignidad de la persona.

En efecto, la noción predominante de sexo recogida continúa siendo la del sexo en sentido físico (biológico, genético, endocrinológico) con la división entre lo masculino y lo femenino; al que se añade, en segundo término un sexo de creación jurídica desde que la norma tiene en cuenta la transexualidad que solo se reconoce cuando se cumplen los requisitos dispuestos.

Entre la intersexualidad, la transexualidad y la homosexualidad existen interconexiones debidas, de una parte al estadio de desarrollo de las ciencias de la vida y del conocimiento, de otra

\footnotetext{
18 El artículo 4 de la Ley española 3/2007, titulado Requisitos para acordar la rectificación, dispone:

"1. La rectificación registral de la mención del sexo se acordará una vez que la persona solicitante acredite:

a) Que le ha sido diagnosticada disforia de género. La acreditación del cumplimiento de este requisito se realizará mediante informe de médico o psicólogo clínico, colegiados en España o cuyos títulos hayan sido reconocidos u homologados en España, y que deberá hacer referencia:

1. A la existencia de disonancia entre el sexo morfológico o género fisiológico inicialmente inscrito y la identidad de género sentida por el solicitante o sexo psicosocial, así como la estabilidad y persistencia de esta disonancia.

2. A la ausencia de trastornos de personalidad que pudieran influir, de forma determinante, en la existencia de la disonancia reseñada en el punto anterior."
} 
por el ocultamiento y sigilo con el que se han abordado todas las cuestiones del sexo y del comportamiento en la sexualidad, y en particular para la intersexualidad por el carácter estigmatizador con el que siempre ha ido acompañada. En todo caso, se explican porque todas son bloque común frente a la normalidad (el modelo), no responden al dimorfismo sexual que ha supuesto la división de los humanos: masculino - femenino y al patrón asumido (impuesto por la cultura) del comportamiento sexual dirigido a la reproducción: la tendencia heterosexual.

\section{Breves Conclusiones}

Pese al avance que ha tenido lugar, las normas no aseguran la protección íntegra de la dignidad de la persona en el ámbito de su identidad.

En general, en los ordenamientos civiles españoles, con mayor o menor extensión, se reconoce el derecho a la identidad de la persona, pero la regulación es fragmentaria, insuficiente.

Tampoco, la publicidad en los registros públicos (Registro civil) es adecuada pues, en este ámbito ni se acomoda a la realidad ni a la protección de la dignidad de la persona.

Se propone la eliminación del dato del sexo en la inscripción registral.

La identidad y autodeterminación exigen la inclusión de la homosexualidad y bisexualidad, en reconocimiento de la libertad de la persona.

El conocimiento de los orígenes en la adopción debe desarrollarse, sobre todo los medios y vías a través de los que se ejercita.

Debe replantearse el anonimato en la reproducción asistida heteróloga.

\section{Bibliografía}

Albaladejo García, M. (1960). Instituciones de Derecho Civil. Parte general y Derecho de obligaciones. Librería Bosch: Barcelona.

Álvarez Gónzalez, S., \& García Rubio, M. P. (2013). Capítulo 9: El nombre de las personas físicas. En M. C. Gete-Alonso y Calera, \& J. Solé Resina (Coords.). Tratado de Derecho de la persona física. Madrid: Civitas, Thomson Reuters.

Balza, I. (2009, enero/junio). Bioética de los cuerpos sexuados: transexualidad, intersexualidad y transgenerismo en ISEGORÍA. Revista de Filosofía Moral y Política, (40).

Batler, J. (2007). El género en disputa, El feminismo y la subversión de la identidad. Traducción Ma Antonia Muñoz. Paidós: Barcelona.

Espín Alba, I. (2008). Transexualidad y tutela civil de la persona. Madrid: Editorial Reus.

Fernández Sessarego, C. (1992). Derecho a la identidad personal. Buenos Aires: Astrea. 
Garriga Gorina, M. (2007, enero/diciembre). El conocimiento de los orígenes genéticos en la filiación por reproducción asistida con gametos donados por un tercero. Revista Derecho Privado y Constitución, (21).

Gete-Alonso y Calera, M. C. (en prensa). Identidad e identificación de la persona.

Gete-Alonso y Calera, M. C., \& Solé Resina, J. (2013). Tratado de derecho de la persona física. Thomson: Civitas.

Jayme Zaro, M. (1999). La identidad de género. Revista Psicoterapia, 10(40), 5-22.

Valls-Llobet, C. (2008). Identidades sexuales en la ciencia y la salud. Actas del Congreso Estatal Isonomía sobre Identidad de Género vs. Identidad Sexual. Universitat Jaume I, Castellón, Espanha, 4.

Valpuesta Fernández, R. (2013). Capítulo 11: La identidad sexual. La homosexualidad. En M. C. Gete-Alonso y Calera, \& J. Solé Resina (Coords.). Tratado de Derecho de la persona física. Madrid: Civitas, Thomson Reuters.

Data da submissão: 22 de março de 2017 Avaliado em: 04 de agosto de 2017 (AVALIADOR A) Avaliado em: 04 de maio de 2017 (AVALIADOR B) Aceito em: 07 de novembro de 2017 
